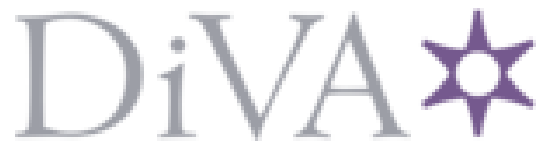

http://www.diva-portal.org

Preprint

This is the submitted version of a paper published in .

Citation for the original published paper (version of record):

Echeverri, P., Salomonson, N. (2017)

Embodied Value Co-Creation: A Turn-taking Perspective on Service Encounter Interactions

Journal of Creating Value, 3(1): 1-17

https://doi.org/10.1177/2394964317693341

Access to the published version may require subscription.

N.B. When citing this work, cite the original published paper.

Permanent link to this version:

http://urn.kb.se/resolve?urn=urn:nbn:se:hb:diva-12074 


\title{
Embodied value co-creation: A turn-taking perspective on service encounter interactions
}

\author{
Authors: \\ Per Echeverria * \\ Nicklas Salomonson ${ }^{\mathrm{b}}$ \\ Affiliations: \\ a Karlstad University \\ CTF, Service Research Center \\ SAMOT Vinn Excellence Center \\ SE-651 88 Karlstad \\ Sweden \\ +46547001505 \\ per.echeverri@kau.se \\ $\mathrm{b}$ University of Borås \\ SE-50190 Borås \\ Sweden \\ +46334354479 \\ nicklas.salomonson@hb.se
}

\section{Contact details:}

* Corresponding author: Per Echeverria

The final, definitive version of this paper has been published in Journal of Creating Value, 3 (1), 2017 by SAGE Publications India Pvt. Ltd, All rights reserved. (C [Per Echeverri and Nicklas Salomonson]

\section{Use the following reference when citing the paper:}

Echeverri, P. and Salomonson, N. (2017). Embodied Value Co-creation: A Turn-taking Perspective on Service Encounter Interactions, Journal of Creating Value. 3 (1), pp. 1-17. doi: $10.1177 / 2394964317693341$ 


\section{Abstract}

This article aims at advancing research on value creation in service marketing by applying theories of turn-taking and multimodality. It is argued that there is a need to uncover what is inherent in the prefix 'co' in value co-creation and that focus needs to be broadened, from perception of value to the production of value-i.e. the specific reciprocal and embodied actions in service encounters.

For the analysis, an empirical study of complex interactions between service providers and customers is used. A practice approach is applied, combining interviews and observations of interactants in situ.

The article identifies four specific turn-taking patterns, ranging from 'simple' to 'elaborated', defined by their character and uncovers how the interactants reciprocally use multiple modes in the production of social outcomes.

Theoretically, the study contributes to more fine-grained explanations to what explains the creation (and destruction) of value.

Keywords: Value co-creation; Service encounter; Interaction; Turn-taking; Embodied action; Non-verbal communication. 


\section{Embodied value co-creation: A turn-taking perspective on service encounter interactions}

\section{Introduction}

The actual interaction between customer and service firm is a central locus in marketing. More specifically, it is in the concrete everyday interplay between these actors that value is created or destroyed for the beneficiary; primarily for the customer, but also for the marketing organization (Grönroos, 2011). The way in which this interplay is accomplished will determine the outcome; something that has been explored in terms of 'interaction value' (Echeverri and Skålén, 2011) or more to the point, an 'interactive relativistic preference experience' (Holbrook, 2006:12) partly produced by the interaction per se, but ideally defined by the customer during usage or interaction due to customer prerogative. This means that the prerequisites for value can be created although not always perceived or felt by the customer as in the case of arrogant or misbehaving customers.

This notion is recognized in the contemporary service and marketing literature, but is still not fully reflected in the literature. Rather, the majority of studies, i.e. the stream of service encounter quality research since the early 80 s traditionally approach services as a perceptual psychological (mental) phenomenon, most often focusing on what customers experience or evaluate in terms of satisfaction, perceived quality, overall nature of behaviour, cues regarding servicescapes, or how consumption attitudes or behaviour patterns change with specific changes in marketing.

However, this perception of the psychological tradition tends to overlook what is actually being accomplished during service marketing interactions, what specific practices of doings and sayings each party uses, what effects these have on the interactants, and how embedded social 
structures are moulded and modified by these practices (Bradley et al., 2013; McColl-Kennedy et al., 2012). To advance service marketing research aimed at more in-depth theories of how value is co-created, we argue that the focus needs to be broadened, from perspectives of perception to the production of service-the latter is the reciprocal provider-customer actions, including the embodied and material elements used in enacting the service. By introducing the term 'embodied' we recognize that human interactions most often include different parts of the body as essential modes. In doing so, we identify, more specifically, how a service provider and a customer, while interacting, influence each other in a way that helps customers to utilize resources better - both their own and those supplied by the provider-including the multimodal (verbal and non-verbal modes) characteristics that are argued to be present as well as crucial to creating customer value in service settings (Andrzejewski and Mooney, 2016; Puccinelli et al. 2013).

The study draws on theories of turn-taking and multimodality and is suitable for analysing interactivity among humans. Turn-taking is a recognized approach within interaction theory, conversation analysis, discourse analysis, ethnomethodology, behaviour and gesture studies, to unfold what happens within human interaction. A "turn" is defined as an action directed at another person (Goodwin, 2006) and recognized as one of the smallest interaction units, crucial for understanding how cultural phenomena and social practices are realized in our social world. Similarly, studying multimodality is recognized as an approach to unfold more specifically the wide range of modes by which individuals interact. Focusing multimodality is relevant as it identifies the elements by which turns are accomplished. It can be a verbal utterance, varyingly complete, a non-verbal indication produced by a body, a face, a gesture or intonation, having an observable effect on the other recipient (Echeverri, 2006; Jung and Yoon, 2011), typically by giving a response back, and also taking the form of a turn (Iwasaki, 2011). 
Exploring this in more depth will inform service and marketing theory, providing more in-depth explanations as to why and how value is co-created and articulate what is hidden within the little prefix "co" as used in value co-creation.

\section{Literature review}

The contemporary view in marketing and service research stipulate that value is co-created as "value-in-use" (e.g. Grönroos, 2008, 2011; Vargo and Lusch, 2008). This view has its roots in the early works of service marketing and is echoed in Grönroos (2011), where it is articulated as a mutual or reciprocal action whereby two or more parties have an effect upon one another. Interactions take place during service encounters and are typically dialogical processes that merge into one integrated process of coordinated action.

However, most contributions in the literature are limited to a more aggregated view on cocreation and in the language of Oliver (2006) service encounter research has been "unidirectional", implying that the co-creation of value between providers and customers has not been systematically studied. Oliver (2006) conceptually (but not empirically) explores the dynamics underlying this symbiosis in terms of mutual satisfaction and bi-directionality, the latter term referring to the assessment and fulfilment of the other party's needs. But contemporary research tends to avoid this and rather analyse interactions as aggregations with attributed meaning.

Based on a recent literature review, Karpen et al. (2012) implicitly address value co-creation dimensions proposing a conceptual framework of mere simpler joint actions: i.e. individuating, relating, empowering, ethical, developmental, and concerted joint actions. Neghina et al. (2015) adds nine antecedents but the framework awaits validation.

This absence of more detailed studies of interactions in service settings is recognized by several scholars in service and marketing research. Bradley et al. (2013) illustrate, in their literature 
review of service encounter behaviours, that research tends to adopt either a customer or an employee perspective, i.e. how the behaviour is enacted by only one party involved in the interaction. They show that employee behaviours have been studied more often than have customer behaviours. In contrast, they examine service interactions from both parties' perspectives, exploring processes of reciprocal influence. Analysing a set of behaviours, they identify a broad category labelled "task" (including: Present issue; Attend to ask; Inform; Instruct; Compensate; Procedural behaviours; Routine acts; etc.). Despite the merits of this approach, the findings do not constitute reciprocal two-way turn-taking interactions.

In a recent article by Skålén et al. (2015) on collaborative practices between a firm and a brand community, three (quite unspecific) practices are identified: i.e. questioning and answering, dialoguing, and translating. No specific interactional patterns are identified. An exception to the lack of interest in the specifics of co-creation in the literature is Salomonson et al. (2012). They focus heavily on cognition and meaning-making in short, verbal voice-to-voice conversations, not including the embodied aspects of interaction or the social outcomes produced during interaction. The merits lie in identifying three value-driving aspects: attentiveness (the listener's behavioural focus on the customer), perceptiveness (the listener's attempt to understand the message by assigning meaning to it), and responsiveness (the level of understanding or agreement between the provider and the customer). However, it provides little information on how these aspects are produced more specifically.

To conclude, the growing body of literature on value co-creation tend to overlook the concrete realization of value. This study aims to more specifically explain it.

\section{Methodology}


For the analysis, a qualitative single-case methodology was used in order to provide rich descriptions and contextual information relevant to the analysis of reciprocal turn-taking activities during service encounters.

\section{Data collection}

Empirical data was used from mobility services for individuals with physical disabilities. The services are characterized by a high level of interaction, longer interactions, and sensitivity to customer prerequisites. They offer a rich arsenal of embodied interactions similar to those found in other service contexts such as healthcare and social services. Interviews were conducted with different informants, in most cases in the field and on the move from door-to-door, in order to grasp contextual information in situ. We deemed this ethnographic approach to be necessary in order to uncover the nuances of the interactions (Miles and Huberman, 2004).

Data collection was conducted in stages. First, we interviewed 11 customers, grasping important contextual factors (functional limitations, life situation, personal needs, and experiences). Following this, we accompanied them on different journeys using mobility services to one or two destinations which they had chosen. The interviews continued during the journey, when they were encouraged to comment on a wide range of issues connected with using the service.

During the journeys, we took field notes and photos, and we documented the interviews by making audio recordings. Video was used when appropriate to document specific interactive procedures. Interviews were completed at destinations. We asked them to reflect on things occurring during their journeys, such as doings and sayings, roles taken, and their experiences of it vis-á-vis their functional limitations. This in situ procedure enabled us to gain access to 
naturally occurring data and contextual information, necessary for an in-depth understanding of what is going on (Silverman, 2006).

As a second stage, in order to gain an in-depth understanding of the service provision per se, we interviewed 9 service providers (drivers) in more or less the same way, applying the doorto-door approach and collecting data while accompanying them in the field for 1.5-2 hours. They were asked to choose and then drive to a couple of destinations that could be seen as representative of their work. During these journeys, and while at the destinations, they were asked to describe their work and to exemplify any interactions with their customers that work particularly well or bad.

During a third stage, we went undercover. With the permission of the service provider, one of the researchers took on the role of a wheelchair-bound customer while the other acted as his personal assistant. Over the course of 10 journeys, we made detailed observations of the service procedure, taking field notes and photos when appropriate (using iPads and smartphones). Using the chosen procedure, we were not recognized as researchers, thus eliminating methodological bias (Czarniawska-Joerges, 2007). This enabled us to observe crucial details and to concentrate on the actual interaction-i.e. on the specific grips, looks, mimicry, body positions, and modalities that are important elements of the production of customer experiences (cf. Silverman, 2006).

\section{Data analysis}

The rich and complex empirical material was analysed in different ways. The interviews were transcribed and coded based on induction, the identification of empirical categories, themes, and variables capable of informing the research questions. Sensitivity to turn-taking patterns and social outcomes guided the ongoing joint collection and analysis of the data. The constant 
comparison of narratives made us sensitive to what was of key importance to the participants. Photos, videos, and field notes were compared and used in parallel. The data was coded nonprejudicially, i.e. without a priori coding schemes and this ended when we experienced theoretical saturation (Strauss and Corbin, 1998). Initial codes were clustered into emerging categories with regard to; i) overall phasing of the encounters, ii) social outcomes, and iii) turntaking patterns. Both authors examined the data individually but discussed the analysis jointly.

The study is grounded in social practice theory, a view advocating that it is through social practices that social phenomena are accomplished and highlights the importance of actors' roles, actions and discursive activities, and their interactions with others. The focus is on practices defined as a pattern of behaviour, consisting of several interconnected elements: bodily and mental activities, the use of 'things', and knowledge in the form of understanding, know-how, states of emotion, and motivational knowledge (Reckwitz 2002).

\section{Findings}

In the following, we first describe and comment briefly on the overall phasing of the service procedure. Second, we describe how participants, both sequentially and in more detail, organize their collaborative interactions turn by turn within these phases, focusing on the specific social outcomes being realized. Finally, we describe four distinct Turn-taking patterns, based on frequency and modality.

\section{Overall phasing of service procedure}

Taking a closer look at the service procedures, five overall phases are identified in all the observed services. First, the interactants mutually organize an approaching phase where both interactants display an initial attempt to getting close to each other, such as customer's positioning on the street (waiting for the driver), the driver's positioning of the vehicle, climbing 
out, and identifying the customer. Second, they frame the meaning and 'rules' of their interplay. This is a form of shaping the interaction before the very core service sequence occurs, e.g. creating a specific meaning in which the interaction is embedded (e.g. 'joyful', 'informal', 'serious', etc.). Third, we identify a phase of delivery; this is the core of the service. In this context, this is when the employee, in cooperation with the customer, supports the customer in a number of activities: i.e. opening the door; getting into the vehicle; taking a seat, or, if in a wheelchair, positioning the customer in an appropriate place aboard the vehicle; securing wheelchairs or other forms of equipment, including bags; assisting with the customer's seatbelt; driving to the customer's destination. Fourth, the phase of finalizing, is identified when the interactants indicate that they are preparing to end the service procedure. This finalizing is enacted upon arrival at the final destination, preparing for and fulfilling the disembarking procedure. Fifth, there is a phase of rounding off. Creating customer value in this phase is associated with politeness, a courtesy towards each other which includes sensitivity regarding tempo and paying due respect to the other individual.

The different sequences are produced and reproduced during interactions; a dialectic relationship between actions and social structures as in most routinized practices. Figure 1 illustrates the five overall phases.

(Insert Figure 1 about here.)

\section{Sequential organisation of social outcomes}

In relation to the five phases, the interactants organize their actions sequentially, turn by turn, based on the specific characteristics of these individual turns. As such, the participants show each other interactional 'know-how', an acquired skill of knowing how to accomplish a service procedure that conforms to the other party's actions, but also to the general human social skills acquired and practiced. During each phase, they co-create different 'social outcomes', realized 
by the ongoing sequences of bodily and verbal turn-taking. In situations where the participants accomplish these social outcomes in accordance with contextual codes of good conduct it generally drives customer wellbeing and, on the employee side, the sense of doing a good job. Grounded in the empirical material, four major social outcomes are identified. These are, by nature, difficult to illustrate, but the following quotations provide some contour to them (see also Figure 2 for an illustration of each social outcome).

(Insert Figure 2 about here.)

The first social outcome is labelled 'adjustment' and is accomplished when the interactants 'read the situation'. It connotes what is socially achieved by the interactants in order to initiate and to make other actions adequate and relevant, as illustrated by the following quote.

You can almost see on people if they want to talk or not... when they laugh and say something when jumping into the cab, then they think it's good to talk... Mostly, you can see it on their body language whether they're satisfied or not... Often, it's a case of "no, not necessary, everything's ok"... "You can drop me off here, I'll walk". "No, I'll drive you. You've got to get there." "Yes, yes, but it's not necessary."

The second social outcome is labelled 'responsivity' and is best described as a relevant response to a former adjustment.

There are different kinds of disabled people so you have to kind of weigh up what to say and what not to say... You try to explain how you get in and... But there's a bit of a combination at work there, you rely on experience there, and then you ask them a few things too if you notice that they want to.

The third social outcome is labelled 'socialization' which, is this context, connotes a specific form of small talk, a social function that displays and actualizes the customer relationship per se. 
And then I pressed [the gas pedal] and then I said "No, it's directly to the western cemetery." "Oh, how boring!” she said. "Ok, what do you mean?", I said. "Well, I think it's a lot of fun to go riding in a car". "Yeah, yeah", I said, "which route do you want to take?" "Well, take the longest route", she said. You're a bit of an on-board host... you have to open up a bit. Otherwise things don't work.

The fourth social outcome is labelled 'emotional charge' and displays the feelings involved.

There was a lady who gave me a telling off all the way. It made me sad and I dropped her off there. And then I thought about it. Bloody hell, what a moaner. And then there are those who become really happy, you know... You can always put them in a good mood... These old biddies, they're often like little girls you know, carrying on and laughing... you say "your hair's nice", that just makes them happy, and all that... I think it's fun and they do too.

The description that follows is a generalized version of a typical turn-taking pattern regarding how social outcomes are continuously reproduced during micro-level interactions, as such providing the prerequisites that lead to the experiencing of value.

\section{Within the approaching phase}

We identify the actual physical encounter between the interactants as a relevant starting point. The service provider (driver) has information on where to go and then leaves the cab to search for and approach the customer. The customer, on the other side and after ordering the service and leaving the house, positions him/herself in an appropriate location (in order for the driver to find him/her) and then approaches the driver. At that very moment, the social interaction starts, with or without verbal utterances, but always with embodied actions.

At a certain point, the interactants 'read the situation', i.e. adjusting to conditions in the specific situation in order to approach the other in a relevant way. Typically, this social outcome is 
realized by glancing at the other (turn 1 and turn 2), checking the conditions, identifying the specific street location of the other, using bodily positions. Then, the driver encounters the customer (turn 3), showing his/her presence and asking for the name and destination (turn 4), while the customer then confirms using a verbal response or simply by nodding (turn 5). After a while they shift to a production of responsivity to the other individual—e.g. by means of the driver telling or implicitly indicating to the customer that things are under control (turn 6). While adjusting is a form of 'reading the other', a search for alignment to situational conditions-responsivity is the reaction to the other individual's action based on the information provided. Somewhere here in the process, the participants typically enter into sequences of small talk, here labelled socialization, to mark a shift away from more instrumental forms of interaction towards more informal person-centric forms (turn 7). Often, this shift is marked by the other by also being more personal or informal (turn 8). Finally, the interactants end the phase by displaying emotional markers-e.g. jokes, smiles, etc. (turn 9), indicating genuine or merely 'scripted' emotions, an emotional charge of the interaction.

\section{Within the framing phase}

The production of social outcomes in the second phase, more or less follow the same pattern. The interactants frame the character ('joyful', 'informal', 'sensitive') of the following interaction by a similar turn-taking procedure, displayed in the way driver talk and leads the customer to the vehicle (turn 10), once again adjusting to the customers' abilities and environmental conditions (turn 11). The customers adjust to the providers actions and in doing so initiate the interactants to produce responsivity e.g. by moving hands gently and with integrity towards the customer if assistance is needed (turn 12). Sometimes, the service provider during this turn use short verbal phrases to let the customer know that things are under control (e.g. "Okay.", "I'll push you now", "I've got you", "Here we are", etc.). Then again the interactants enter into socializing (turn 13), crossing a boundary of personal integrity and 
becoming informal. As during the previous phases, the interactants typically charge the interaction with emotional markers such as smiles, touches (turn 14), various mimicry, a display of positive or negative emotional charge.

\section{Within the delivering phase}

In the core of the service, again the four distinct social outcomes are produced. To deal with specific attachment of seatbelts, handling of bags, adjustment of seats and headrests, securing of wheelchairs, or dealing with other equipment (turn 15), the service provider adjusts to the customer's functional prerequisites and needs. Responsivity is displayed during the interactants' timely communication, asking each other questions and checking on comfort, speed, etc. (turn 16), while embedding for socialization in the form of small talk, personal comments, telling of anecdotes (turn 17), directly triggering the emotional charging of customer delight or dissatisfaction (turn 18).

\section{Within the finalizing phase}

When things are to be finalized, the service provider adjusts not only to the planned delivery point, but also to the exact location in the street environment (turn 19), appropriately facilitating the customer's up-coming movements outside the vehicle (turn 20). The display of responsivity to specific needs using questions and gazing (turn 21) may again lead to socializing, by e.g. use of a simple touch of the customer's shoulder (turn 22). The finalization is emotionally charged by, for instance, a tilted head or a specific intonation indicating positive warmth and care, or a negative insensitive behaviour (turn 23).

\section{Within the rounding off phase}

Just before the interactants separate, we observe something that stands out. Instead of just turn around, the service providers typically round off the service encounter by waiting for the customer (just a few seconds) by means of standing/sitting still, lifting their eyebrows, or just 
uttering with heightened intonation, e.g. "You okay now?" (turn 24), thus inviting the customer to take a finalizing initiative by declaring, or just indicating, that everything is okay and satisfactory and that he/she will be able to manage things on his/her own. This awaiting is an adjustment to the other's process, leading to confirmation through a quick nodding gesture displaying responsiveness (turn 25), and round off by socializing utterances such as "Take care" or "See you next time" (turn 26). Again, the service encounter is emotionally charged with markers of joy, seriousness, or a state of being bored (turn 27).

As shown, the service encounters are reciprocal and produced turn by turn, sequentially producing a specific set of social outcomes. Normally, interactions result in positive experiences and a sense of wellbeing for both actors. However, the empirical material reports numerous examples where one, or both, of the actors misbehave. For an overview of the sequential organization of different social outcomes in relation to overall phasing, turn-by-turn, see Table 1.

(Insert Table 1 about here.)

\section{Turn-taking patterns}

Taking a closer look at the turn-taking, we identify four principle interactional patterns: 1 Simple; 2 Substantial; 3 Intensive; and 4 Elaborated. We argue that the provided patterns of turn-taking illustrate typical ways by which the sequential organisation of social outcomes is organised and ultimately influences the forming of value during interaction. As will be evident in what follows, we identify an interactional initiative-response procedure grounded in the narratives. See Figure 1.

(Insert Figure 3 about here.)

Simple turn-taking: A basic interactional pattern is characterized by a limited number of interactional turns, providing information back and forth. Often, it is a verbal utterance or a 
specific spatial position communicating something of relevance to the other party, followed by a response confirming the first person's initiative. What is also significant for this simple turntaking interaction is the use of quite a few modalities that express needs or intentions during the situation, as in the following example taken from an interview with a customer, a mother accompanying her son during a travel.

He [the driver] lifts my son into the car, puts on his belt, closes the door, goes to the other side, asks my boy - Can you manage by yourself? "Yes" [says my boy]! - "Good" [says the driver]. Then he asks me - "Are you ready?" - "Yes" [I reply]. - "Good, let's go."

Typically, the parties use simple words (e.g. “yes", "right?”, "here”, “there we are”, “okay?”, “thank you", or just step out of the car, looking at each other, etc.).

Substantial multimodal turn-taking: A second interactional pattern is also characterized by the use of just a few interactional turns but significant for this is the use of a wide range of modalities that display needs or intentions during the situation. Typically, the parties take a much longer turn, using a myriad of modalities (more words, looks, mimics, gestures, and postures) as the following quote from a passenger illustrates.

And then I say: - It's just an indication [pointing at stomach] that I feel pretty bad [pulling a face]. Then he shows [with a gesture of resignation] that I'm an irritating passenger [looking down]. But he [slowly] moves his jacket away from the front seat [sighing] which I interpret as an 'okay then sit there'. So I do that [getting into front seat] and then he gets really furious at me [showing an angry face] and starts yelling [using a loud voice], explaining what to do and not to do and all that kind of stuff.

During a brief exchange, due to the richness of communication, each party interacts more fully and is thus more informative. 
Intensive turn-taking: In relation to the two previous forms of interaction, this third form is characterized as high in frequency but not as substantial in terms of modalities. Each party interacts by using lots of turns, back and forth, each turn carrying less information. Typically, this type of interaction uses simple words or embodied markers, as in this quote from a passenger describing a normal interaction.

Well, it's the usual story, I say "Hi" and they say "Hi". And then they ask how things are and I say "Thanks I'm fine". Then they sort out the attachments and continue talking and I answer them every now and then. Then they usually ask how I want the bags and the [safety] belt and so on. I answer and they adjust it [the safety belt], all the time asking if it's ok or if they should tighten it a bit more? And I tell them how I want it. That's how it goes.

The quote illustrates how the conversation goes back and forth, using multiple brief questions and answers, replying to a myriad of different utterances. Due to the high frequency, the interaction is also quite informative, but longer.

Elaborated turn-taking: Finally, interaction may be characterized as both substantial and high in frequence, i.e. elaborated in both dimensions. Typically, such an interaction pattern is informative to both parties, takes more time, and involves the other interactant to a much higher degree. The following utterance from a driver illustrates this.

Once, an old lady with a personal assistant said: - And here comes a happy driver [displaying joy]. - Yes, so far, I am happy [smiling]. But I didn’t mean anything by it, I just looked happy. I had pushed the wheelchair and attached it and everything ... checking that she was fastened safely [using] the headrest. After some 10 metres, she started to yell: - The wheelchair's moving [displaying fear]! - No, it isn't. It adjusts automatically using these automatic belts in the back, I told her. - They just sound that way. - Now we can start, I said? - Yes, she said. But after another 10 metres or so she yelled again at me saying: - I 
had to check again she said insistently. So I went out and checked the attachment. Then she said: - No, I can't go anywhere if it's going to be like this [displaying fear]! I said: - I can't do any more now. She was upset [showing an angry face]. I was frustrated and slammed the door.

These four patterns are to be found during all five phases. As such, they represent generic patterns of turn-taking.

\section{Discussion}

What stands out in our findings is the fact that service interactions are embodied, something that is overlooked in previous research into value co-creation research. The interactants, both the service provider and the customer, use a wide range of non-verbal modalities while interacting with each other turn-by-turn. Examples of this include the frequent use of specific looks, gestures, body positions, movements, intonations, pauses, etc. beyond verbal utterances. The use of these drives the interaction forward, step-by-step, directly influencing the ongoing production of social outcomes. The process is dynamic and gradually adds to the holistic experience of the customer's and employee's wellbeing. The interactants have the capacity to evaluate, not only the situation as a whole, but also the interaction within specific phases. A small blunder during one phase of a service encounter may colour the overall service experience.

In general, the interviews and observations indicate that the more elaborately the provider and the customer interact-i.e. more frequent interaction, in terms of numbers of turns, and greater exploitation of the embodied modalities - the more informative they are and the more wellbeing is indicated. However, in some cases, our findings point in the opposite direction. Some turntaking patterns, containing a substantial amount of modalities and a high number of turns, 
actually destroy wellbeing, as is the case when one or both of those involved display anger or dominance, or violate the integrity of the other. Taking a closer look at each of the four patterns, all of them have the capacity to both create and destroy wellbeing during the interaction. Thus, we are forced to conclude that these four patterns should only be recognised as a classification of different potential value creating turn-taking patterns.

Theoretically, this is important. The four patterns do not describe or explain how value is realized during service encounters; rather, they describe and explain the prerequisites for creation and destruction of value. They represent a characterization of the mechanisms, not specific value drivers. This is also true of the sequential organization of social outcomes. We conclude that they give structure to interactive turn-taking, and that turn-taking reproduces these structures. As such, they constitute service co-creation.

By approaching value co-creation during service encounters, having a turn-taking perspective, we illustrate that service encounters are more than just 'meetings' or even 'interactions' (bidirectional, two-way activities). Service encounters are mutual shaping, i.e. an individual action (turn) directly shapes the contour of the next action (turn). Turn-taking patterns connote the partial moulding of one's own and other individuals' actions, an interdependence of sociallyembedded actors. This is an ontological statement meaning that we cannot understand interactants' actions (turns) in isolation; rather, they have a symbiotic character.

We argue that our findings contribute to a new type of theoretical field of value co-creation in service which has to do with reciprocity in its purest sense-i.e. its actual constitution, not just another word for the vague concepts of 'human exchange' or 'interaction', which generally denote something vague, a mysterious residual regarding what people do down there on the micro-level. Unfolding this in service research provides conceptual tools for analysing and explaining what is "co-" in value co-creation. Theorizing this phenomenon on this sub-level 
will support managers by giving them more detailed descriptions of how things work and, in turn, how things may be managed more effectively. Providing employees with "tools of multimodality", enabling them to better know how to act during specific phases of the interaction, and during specific turn-taking episodes in order to enhance wellbeing, can make the value co-creation process more straightforward.

\section{Conclusion and contribution}

The study addresses the crucial reciprocal mechanisms underpinning value co-creation. Using a turn-taking and multimodal perspective, the findings shed light on how this mechanism looks, providing insights that advance theory due to the bulk of existing service research tending to overlook such in-depth mechanisms.

It is rather notable that service research has paid so little attention to what occurs de facto in concrete micro-level service encounter interactions, beyond customer perceptions. The study unfolds the inherent reciprocity of the prefix "co" as used in value co-creation paradigm. We conclude that service encounters are sequentially organised, both as regards the overall phases and the specific social outcomes produced during the process. The study reveals inherent turntaking patterns, ranging from 'simple' to 'elaborated', defined by their nature in two dimensions - i.e. substance (the number of modalities) and interaction (the number of turns). As such, the study provides in-depth insights in how value co-creation, here measured in terms of wellbeing, is realized and explained.

In doing so, we contribute to research into value co-creation in service research in different ways. First, the findings de-mystify the phenomenon of value co-creation and is a response to the continued calls for closer empirical analysis of everyday micro-level service interactions 
(Echeverri and Skålén, 2011; Neghina et al., 2015; McColl-Kennedy et al., 2012; Oliver, 2006; Sweeney et al. 2015). Theoretically, it uncovers some ontological elements of co-creation.

Second, and in relation to the literature on value co-creation, the findings extend Vargo and Lusch's (2008) work on the centrality of customers' co-creation of value by specifying turntaking activities during the interplay between customers with functional disabilities and frontline employees. Our study adds to the typologies identified by Echeverri and Skålén (2011), unfolding micro-elements within the actual DNA of service practices, that informs procedures, understandings, engagement, and how these micro-elements are related to specific service actions that exist in a dialectical relationship with structures containing overall phases and social outcomes. The findings provide a fine-grained and useful classification in that they include reciprocal aspects, beyond the cognitive and emotional dimensions of practices.

We also add to the work of Neghina et al. (2015), on co-creation as a joint action, by specifying the specific embodied nature of joint action, specifically the mutual sequencing of turn-taking. In relation to McColl-Kennedy et al. (2012) and Sweeney et al. (2015), on customers' own value co-creation activities, we address co-creation as a dyadic issue.

In relation to research into collaborative practices (Skålén et al., 2015), we specify the content of "interaction practices". Instead of a simple tripartite set of practices, our study provides a more fine-grained structure of turn-taking patterns, especially as regards the element of understanding (know-how), unfolding the social outcomes of adjustment, responsivity, and socializing. And, rather than focusing on re-alignment strategies based on separate elements of practices (procedures, understandings, and engagements), we focus on how all these elements are intertwined and embodied. Further, in relation to Skålén et al. (2015), we argue that there is also a need to create strategies that align procedures, understandings, and engagement, and not just to view value co-creation as a result of separate alignment strategies. We argue that, in 
developing such strategies, we need to consider situational and material aspects to a very great degree.

Finally, our findings point to the inherent multimodal components (the verbal and nonverbal elements) embodied in the turn-taking procedure of the interactants, these being important components by means of which the interactants form their turn-taking patterns. We provide illustrations of how these are intertwined. In doing so, we add to the findings of Salomonson et al. (2012).

The study provides some implications for managers and front-line employees, but also for customers. The provider side may need to go beyond the mere managerial discourse on being "service-minded", and may also need to pay more attention to the embodied, behavioural, multimodal, and sequential aspects during training and education since these are important mechanisms for customer and employee wellbeing. The myriad of subtle multimodal elements (hands, gestures, body positions, etc.) included in the study and frequently used by interactants during interactions in producing well-being at customer level, need to be 'orchestrated', managed in congruent ways and in accordance to customer preferences. On the customer side, the insights provided may guide individual customers in how to adapt to different service providers accurately turn-by-turn (in their efforts to serve), and guide them on how to more distinct and actively use the human and material resources provided in different service settings.

The study has some limitations. The distinct nature of value co-creation reported on here, is grounded in an empirical material of mobility service. However, we argue that the findings on an analytical level are applicable to a wide range of similar service settings, such as healthcare, social services, dental care, restaurants, education, etc. 


\section{References}

Andrzejewski, S. A., \& Mooney, E. C. (2016). Service with a smile: Does the type of smile matter? Journal of Retailing and Consumer Services, 29, 135-141.

Bradley, G. L., Sparks, B. A., Zapf, D., McColl-Kennedy, J. R., \& Jimmieson, N. L. (2013). Task-Relationship-Self: A Framework for Understanding Service Encounter Behaviors. Psychology \& Marketing, 30(6), 512-528.

Czarniawska-Joerges, B. (2007). Shadowing: and other techniques for doing fieldwork in modern societies. Copenhagen Business School Press DK.

Echeverri, P. (2006). Service Encounter Analysis Based on Customer Retrospection. Involving Customers in New Service Development, 11, 187.

Echeverri P and Skålén P (2011) Co-creation and co-destruction: A practice-theory based study of interactive value formation. Marketing Theory 11(3): 351-373.

Goodwin, C. (2006). Human sociality as mutual orientation in a rich interactive environment: Multimodal utterances and pointing in aphasia. Roots of human sociality: Culture, cognition and interaction, 97-125.

Grönroos C (2008) Service logic revisited: Who creates value? And who co-creates? European Business Review 20(4): 298-314.

Grönroos C (2011) Value co-creation in service logic: A critical analysis. Marketing Theory 11(3): 279-302.

Holbrook MB (2006) ROSEPEKICECIVECI versus CCV: The Resource-operant, Skillsexchanging, Performance-experiencing, Knowledge-informed, Competence-enacting, Co-producer-involved, Value-emerging, Customer-interactive View of Marketing versus the Concept of Customer Value: “I Can Get It for You Wholesale'. In: Lusch RF and Vargo SL (eds) The Service-Dominant Logic of Marketing: Dialog, Debate and Directions. Armonk, NY: M. E. Sharpe. pp. 208-223. 
Iwasaki, S. (2011). The multimodal mechanics of collaborative unit construction in Japanese conversation. Embodied interaction: Language and the body in the material world, 106120.

Jung, H. S., \& Yoon, H. H. (2011). The effects of nonverbal communication of employees in the family restaurant upon customers' emotional responses and customer satisfaction. International Journal of Hospitality Management, 30(3), 542-550.

Karpen IO, Bove LL and Lukas BA (2012) Linking Service-Dominant Logic and Strategic Business Practice: A Conceptual Model of a Service-Dominant Orientation. Journal of Service Research 15(1): 21-38.

McColl-Kennedy JR, Vargo SL, Dagger TS, Sweeney JC and van Kasteren Y (2012) Health care customer value cocreation practice styles. Journal of Service Research 15(4): 370389.

Miles, M. B., \& Huberman, A. M. (2004). Qualitative data analysis. London: Sage.

Neghina, C., Caniëls, M. C. J., Bloemer, J. M. M., \& van Birgelen, M. J. H. (2015). Value cocreation in service interactions. dimensions and antecedents. Marketing Theory, 15(2), $221-242$

Oliver RL (2006) Co-producers and Co-participants in the Satisfaction Process: Mutually Satisfying Consumption. In: Lusch RF and Vargo SL (eds) The Service-Dominant Logic of Marketing: Dialog, Debate and Directions. Armonk, NY: M. E. Sharpe, pp. 118-27.

Puccinelli, N. M., Andrzejewski, S. A., Markos, E., Noga, T., \& Motyka, S. (2013). The value of knowing what customers really want: The impact of salesperson ability to read nonverbal cues of affect on service quality. Journal of Marketing Management 29(3-4), 356373.

Reckwitz A (2002) Towards a Theory of Social Practice: A Development in Cultural Theorizing, European Journal of Social Theory 5(2): 243-62. 
Salomonson, N., Åberg, A. and Allwood, J. (2012). Communicative skills that support value creation: A study of $\mathrm{B} 2 \mathrm{~B}$ interactions between customers and customer service representatives, Industrial Marketing Management 41 (1), 145-155.

Silverman, D. (2006). Interpreting qualitative data: Methods for analyzing talk, text and interaction. Sage.

Skålén, P., Pace, S. and Cova, B. (2015), Firm-Brand Community Value Co-creation as Alignment of Practices, European Journal of Marketing, Vol. 49, No 3/4.

Sweeney JC, Danaher TS, and McColl-Kennedy JR (2015) Customer Effort in Value Cocreation Activities: Improving Quality of Life and Behavioral Intentions of Health Care Customers. Journal of Service Research 18(3): 318-335.

Vargo SL and Lusch RF (2008) Service-dominant Logic: Continuing the Evolution. Journal of the Academy of Marketing Science 36(1): 1-10. 


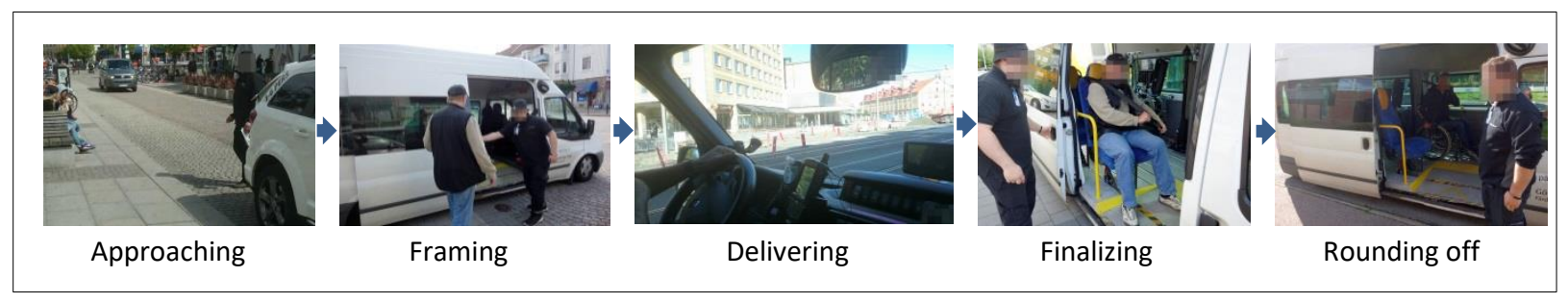

Figure 1. Five overall phases.

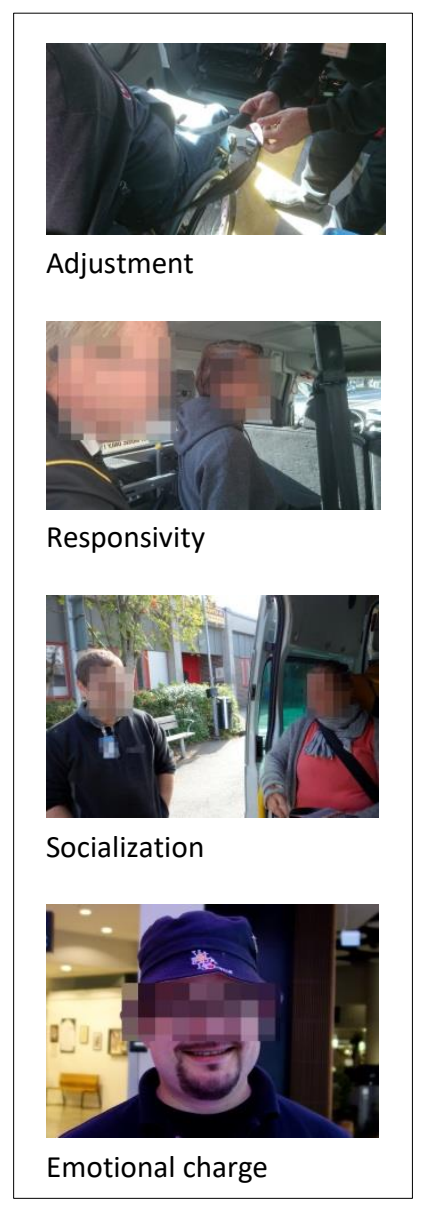

Figure 2. Four classes of social outcome continuously produced during micro-level interaction. 


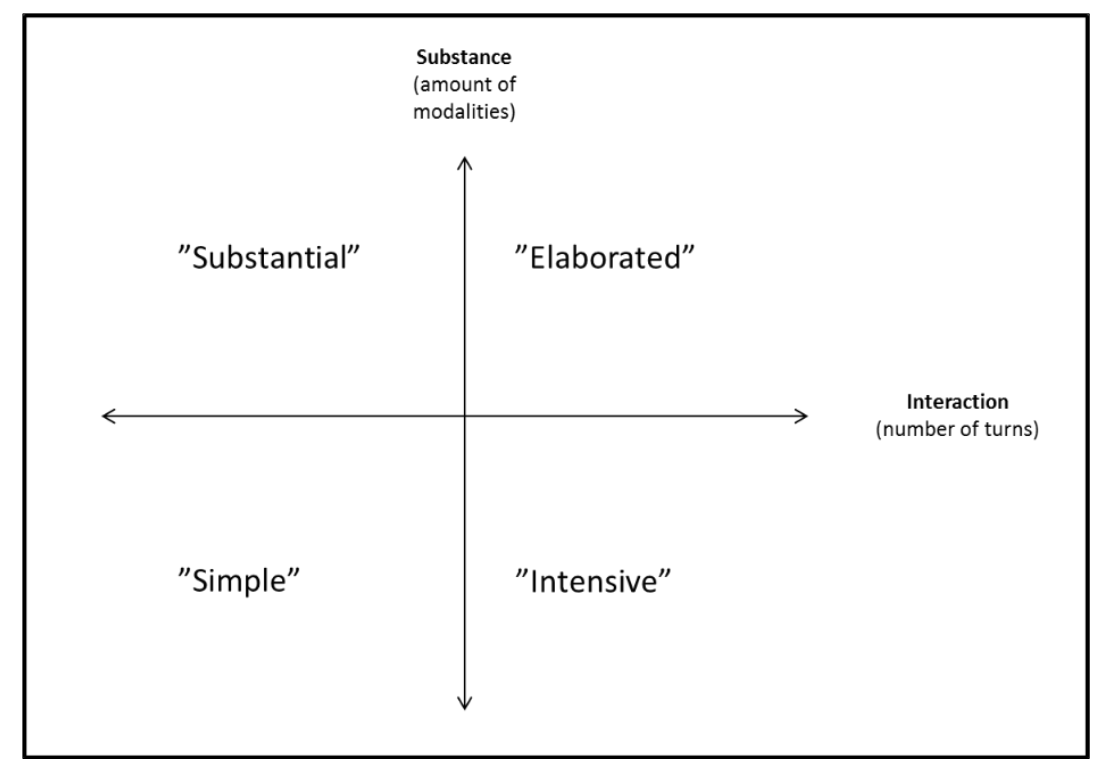

Figure 3. Patterns of turn-taking.

\begin{tabular}{|l|l|l|l|l|l|}
\hline $\begin{array}{l}\text { Sequential } \\
\text { organization of } \\
\text { social outcomes }\end{array}$ & \multicolumn{1}{|l|}{ Overall phasing of service procedure } \\
\hline & $\begin{array}{c}\text { Phase 1 } \\
\text { Approaching }\end{array}$ & $\begin{array}{c}\text { Phase 2 } \\
\text { Framing } \\
\text { (Embarking) }\end{array}$ & $\begin{array}{c}\text { Phase 3 } \\
\text { Delivering } \\
\text { (Driving) }\end{array}$ & $\begin{array}{c}\text { Phase 4 } \\
\text { Finalizing } \\
\text { (Disembarking) }\end{array}$ & $\begin{array}{c}\text { Phase 5 } \\
\text { Rounding off }\end{array}$ \\
\hline $\begin{array}{l}\text { 1 Adjustment } \\
\text { 3 Responsivity }\end{array}$ & Turn 1-5 & Turn 10-11 & Turn 15 & Turn 19-20 & Turn 24 \\
4 Emotionalization & Turn 6 & Turn 12 & Turn 16 & Turn 21 & Turn 25 \\
Turn 13 & Turn 9 & Turn 14 & Turn 18 & Turn 23 & Turn 26 \\
\hline
\end{tabular}

Table 1. Sequential organisation of social outcomes in relation to the phases of service procedures. 